\title{
ENVIRONMENTAL AND ENERGY ASSESSMENT OF NEW VEHICLE TECHNOLOGIES IN THE GREATER ATHENS AREA
}

\section{XIOURAS}

A. ANGELIS-DIMAKIS
G. ARAMPATZIS
D. ASSIMACOPOULOS

Received: 05/12/11

Accepted: 09/03/12

\author{
Environmental and Energy Management Research Unit \\ School of Chemical Engineering \\ National Technical University of Athens \\ 9 Heroon Polytechniou str., Zografou Campus \\ Athens, GR-15780, Greece
}

*to whom all correspondence should be addressed: e-mail: assim@chemeng.ntua.gr

\section{ABSTRACT}

The transport sector in Greece has the largest share in the final energy consumption and the resulting emissions are one of the main sources of atmospheric pollution. This situation is worse in the region of Attica, where nearly half of the country's private cars circulate in an area equal to $3 \%$ of the total country area; the region's climatic and geomorphological characteristics further aggravate the environmental problem.

This paper examines energy saving and environmental impacts reduction from the penetration of eco-friendly technology passenger cars in this region. Three vehicle technologies are considered: (i) conventional hybrid electric vehicles, (ii) battery electric vehicles and (iii) fuel cell electric vehicles. The influence of the driving cycle is examined through the comparison of two different cycles, the New European Driving Cycle (a regulatory driving cycle) and the Athens Driving Cycle, based on actual driving data.

Two alternative scenarios are formulated. The first involves the substitution of all the passenger cars that were registered during the last year (2010) with hybrid and battery electric vehicles that already exist in the Greek market. The second scenario examines the penetration of fuel cell electric vehicles. Both scenarios are evaluated on the basis of their expected energy savings and greenhouse gas emissions reduction. A $7.5 \%$ to $9 \%$ reduction of the $\mathrm{CO}_{2}$ emissions is expected, for the Athens Driving Cycle, if these measures are applied in a five year period.

KEYWORDS: Transport Sector, Energy Savings, GHG Emissions, Greater Athens Area.

\section{INTRODUCTION}

Intense urbanization and economic growth of the past decades has excessively increased the demand for transport vehicles (mainly for private and less for public transport vehicles) and longer road networks. This trend has resulted in a serious increase of the final energy consumption and transport sector has become one of the main sources of atmospheric pollution. Road transportation is responsible for $70 \%$ of the CO emissions, for about $50 \%$ of HC emissions and VOCs, and for about 35\% of the NOx emissions in the country (MINENV, 2009), and these percentages are higher in urban areas.

The situation is even worse in Greece, as the increase refers mostly to internal combustion vehicles using gasoline or diesel. In 2008 the vehicle fleet was doubled comparing to 1990, with the share of medium and heavy load vehicles having significantly increased (from $15 \%$ in 1990 to $35 \%$ in 2008). Subsequently, $\mathrm{CO}_{2}$ emissions from 1990 to 2008 show a $68 \%$ increase and $\mathrm{N}_{2} \mathrm{O}$ emissions an $85 \%$ increase. At the same period fuel consumption in the transport sector has increased by $71 \%$. The problem is more acute in the region of Attica, where almost half of the country's private cars circulate in an area equal to $3 \%$ of the total country area (MINENV, 2009). 
In the recent years, the automotive industry focuses on eco-friendly technology, the realization of zero pollution and the development of green vehicles by increasing system energy efficiency and reducing exhaust emissions (Xiaolan et al., 2011). As a result new advanced vehicle technologies have been developed and implemented, using alternative fuels such as hydrogen, biofuels and/or electricity, which would ultimately reduce the emissions and energy consumption.

The objective of the present paper is the assessment of the penetration of new technology passenger cars in the transport sector of Greater Athens Area, towards energy savings and reduction of the green house gas (GHG) emissions. Three vehicle technologies are examined:

- Hybrid electric vehicles (HEVs), that improve fuel economy, offer low emissions and take the advantage of existing fuel infrastructure.

- Battery electric vehicles (BEVs), which are more energy efficient, have zero tail pipe emissions but have higher cost, limited travel range and lack of recharging infrastructure.

- Fuel cell electric vehicles (FCEVs), which when combined with the right source of energy (hydrogen) have the highest potential efficiencies and lowest emissions of any vehicular power source.

The HEVs and BEVs have already been introduced in the market but their share in the total vehicle fleet is still low (less than $1 \%$, AMVIR, 2010). On the other hand, it is currently believed that FCEVs need at least five more years of testing and improvement before large scale commercialization can begin. Economic and environmental analyses show that FCEVs will likely be both economically competitive and environmentally friendly and the transition of the transportation sector to the use of FCEVs will represent one of the biggest steps to ward the hydrogen economy (Veziroglu and Macario 2011).

\section{METHODOLOGY DESCRIPTION}

The energy and environmental assessment of vehicles is based on two models. First, an energy consumption model is used to calculate the vehicle's fuel and/or electricity consumption over various driving cycles. Second, a vehicle design model is used to estimate component sizes necessary to satisfy specific performance constraints. The vehicle design model couples the energy consumption model, to be able to capture mass compounding in the sizing of components.

\subsection{Energy Consumption Model}

The energy consumption model is based on the Parametric Analytical Model of Vehicle Energy Consumption (PAMVEC) (Simpson, 2005), that predicts vehicle energy consumption on the basis of a parametric driving cycle description, total vehicle mass, other attributes of the vehicle platform (such as drag coefficients and accessory loads) and the power train component efficiencies.

A diagram of the generic power train architecture is shown in Figure 1. HEVs, FCEVs and the conventional internal combustion vehicles (ICVs), incorporate a fuel engine that provides the energy required to complete a driving pattern. The engine is capable of handling mono-directional power flows only. HEVs incorporate an electric motor that provides peak power capability, in addition to the engine. On the other hand, BEVs rely solely on the electric motor. The motor/battery component also acts as an energy buffer mechanism that can be used as a generator to charge the battery by either the regenerative braking or absorbing the excess power from the engine when its output is greater than that required to drive the wheels.

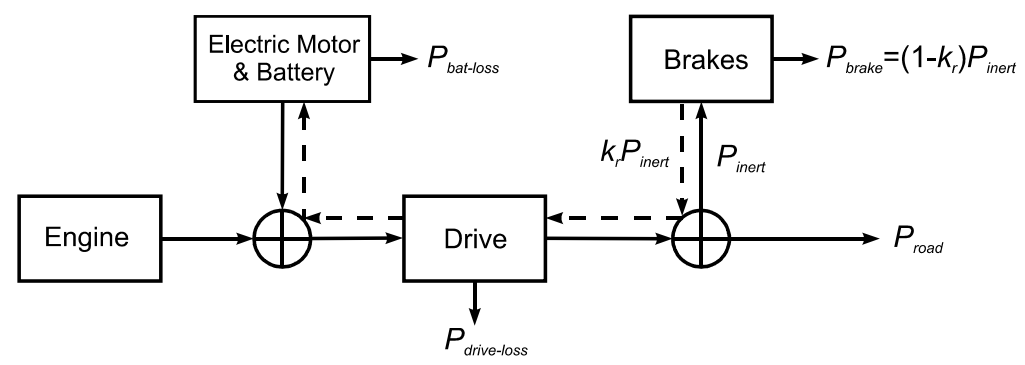

Figure 1. Generic power train architecture of a vehicle 
The average power input requirement that must be provided by the engine and/or the electric motor $\left(P_{\text {tot }}\right)$ is calculated as follows:

$P_{\text {tot }}=P_{\text {road }}+P_{\text {brake }}+P_{\text {drive-loss }}+P_{\text {bat-loss }}+P_{\text {acc }}$

Where $P_{\text {road }}$ is the power required to overcome drag and friction forces, $P_{\text {brake }}$ is the braking losses, $P_{\text {drive-loss }}$ is the drive train losses, $P_{\text {bat-loss }}$ is the losses during the regenerative action of the electric motor and $P_{a c c}$ is the power supplied to the accessories of the vehicle. The expressions for the first four terms in the above equation are:

$$
\begin{aligned}
& P_{\text {road }}=\frac{1}{2} \rho C_{D A} v_{r m c}^{3}+C_{R R} m_{\text {tot }} g v_{\text {avg }} \\
& P_{\text {brake }}=\left(1-k_{r}\right) P_{\text {inert }} \\
& P_{\text {drive-loss }}=\frac{1-\eta_{\text {drive }}}{\eta_{\text {drive }}}\left(P_{\text {road }}+P_{\text {inert }}\right)+\left(1-\eta_{\text {drive }}\right) k_{r} P_{\text {inert }} \\
& P_{\text {bat-loss }}=\frac{\left(1-\eta_{\text {bat }}\right)\left(1+k_{r}\right)}{2} P_{\text {inert }}
\end{aligned}
$$

where $C_{D A}$ the drag area (the product of aerodynamic drag coefficient and the frontal area), $C_{R R}$ the rolling resistance coefficient, $m_{\text {tot }}$ the total vehicle mass, $\eta_{\text {bat }}$ and $\eta_{\text {drive }}$ the efficiencies of the battery and the drive train and $k_{r}$ the regenerative braking fraction. The term $P_{\text {inert }}=k_{m} m_{\text {tot }} \alpha_{c h} v_{\text {avg }}$ represents the average rate of kinetic energy storage in the vehicle inertia, where $k_{m}$ is a factor to account for the rotational inertia of the power train. ICVs and FCEVs, that lack a regenerative buffer mechanism, have $k_{r}=0$ and $P_{\text {bat-loss }}=0$.

A novel feature of the above equations is the use of only three parameters to fully characterise the driving pattern during the total trip time $T$ :

$$
\begin{array}{ll}
v_{\text {avg }}=\frac{1}{T} \int_{0}^{T} v d T & \text { Average Velocity } \\
v_{r m c}=\sqrt[3]{\frac{1}{T} \int_{0}^{T} v^{3} d T} & \text { Root-Mean-Cube Velocity } \\
\alpha_{c h}=\frac{1}{2} \frac{\sum\left(v_{\text {final }}^{2}-v_{\text {initial }}^{2}\right)}{v_{\text {avg }} T} & \text { Characteristic Acceleration }
\end{array}
$$

\subsection{Vehicle Design Model}

The vehicle design model estimates the power train component sizes on the basis of four input performance constraints: (i) top speed, (ii) gradability, (iii) standing acceleration and (iv) driving range. It is based on an iterative procedure (Figure 2) for estimating the total vehicle mass, which is a key contributor to overall energy consumption.

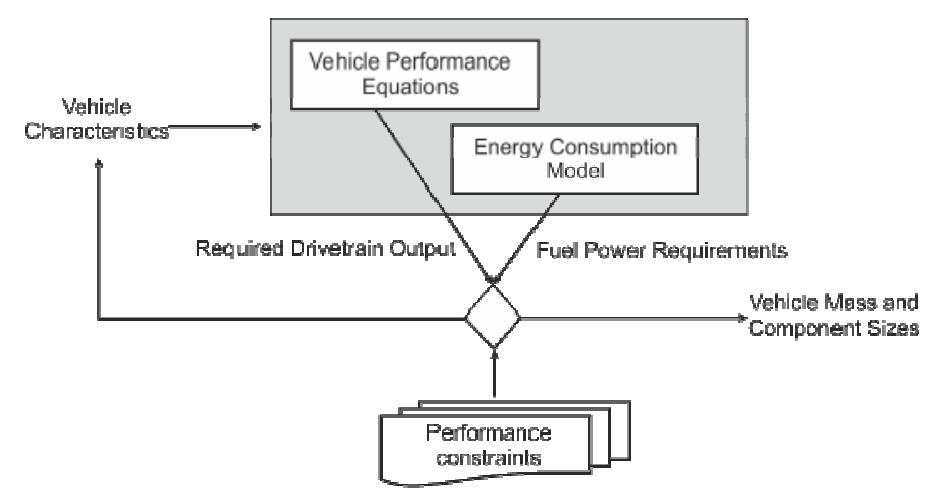

Figure 2. The vehicle design model 
The expression for the total mass of a vehicle is given by:

$m_{\text {tot }}=m_{\text {glider }}+m_{\text {cargo }}+k_{\text {struct }} m_{\text {powertrain }}$

The parameters $m_{\text {glider }}$ and $m_{\text {cargo }}$ are considered constant. Since different power train architectures utilize different components, the expressions for $m_{\text {powertrain }}$ are different. The parameter $k_{\text {struct }}$ accounts for the mass of additional structural support that may be required to support the power train.

The crucial element in the vehicle design model is to relate the total vehicle mass to the performance criteria. This relation, for the first three constraints, is given by the following vehicle performance equations, specifying the required drive train output:

$$
\begin{array}{ll}
P_{\text {drive-out }}=\frac{1}{2} \rho C_{D A} v_{t s}^{3}+C_{R R} m_{\text {total }} g v_{t s} & \text { Top speed } \\
P_{\text {drive-out }}=\frac{1}{2} \rho C_{D A} v_{g r}^{3}+C_{R R} m_{t o t} g v_{g r}+m_{t o t} g Z_{g r} v_{g r} & \text { Gradability } \\
P_{\text {drive-out }}=\frac{N^{2}+1}{N^{2}} \frac{k_{m} m_{\text {tot }} v_{\text {acc }}^{2}}{2 t_{\text {acc }}}+\frac{1}{2}\left(\rho C_{D A} v_{\text {acc }}^{3}+C_{R R} m_{\text {tot }} g v_{\text {acc }}\right) & \text { Acceleration }
\end{array}
$$

Where $v_{t s}$ is the required continuous top speed, $Z_{g r}$ the required gradability at the speed of $v_{g r}, t_{a c c}$ the time taken to accelerate to the terminal speed $v_{a c c}$, and $N$ is the drive train over speed ratio. More details on the relation between $P_{\text {drive-out }}$ and $m_{\text {powertrain }}$ for different vehicle technologies can be found in Simpson (2005).

The driving range constraint specifies the size of the vehicle's energy storage system (engine and/or battery). For vehicles with a fuel tank, the size of the energy storage system (in Wh) is related to the average flow of fuel (calculated by the energy consumption model) as follows:

$$
E_{\text {fuel }}=\text { range } \frac{P_{\text {tol }} / \eta_{\text {engine }}}{v_{\text {avg }}}
$$

Where range is the driving range requirement and $\eta_{\text {engine }}$ the efficiency of the engine

\section{CASE STUDY - GREATER ATHENS AREA}

\subsection{Driving Cycle}

The calculation of energy consumption by passenger cars is usually based on the New European Driving Cycle (NEDC) (Figure 3.a). This cycle is assembled from major European capitals traffic data (Paris and Rome) and is applied in laboratory test approvals in the EU. Traffic data from Athens was not included in the development of NEDC. All road traffic in Athens encounters significant delays and small speeds, which lead to long travel times. Traffic congestion and delays are not helped by the fact that a significant percentage of roads are either narrow or at large grade. It has been estimated that the overall daily average corresponding traffic speed throughout the main urban areas is about $23 \mathrm{~km} \mathrm{~h}^{-1}$, while the average speed in the remote suburbs is $35 \mathrm{~km} \mathrm{~h}^{-1}$ and in the semi-rural areas 52 $\mathrm{km} \mathrm{h}^{-1}$. Speeds during the peak hours and on the central region are much lower, though in many cases less than $10 \mathrm{~km} \mathrm{~h}^{-1}$ (Arampatzis et al., 2004).

Recent studies (Pitsas, 2003) have shown that the European driving cycle is not suitable for the emission and fuel consumption estimation for passenger cars driven in Attica Basin. That is why the Athens Driving Cycle (ADC) (Figure 3.b), has been developed, based on actual driving data, collected in the whole area of the Attica basin seven days a week from 6:00 until 24:00. Fuel consumption showed an increase for ADC compared to NEDC in percentages that vary from $56 \%$ to about $79 \%$ (Tzirakis et al., 2006).

Both driving cycles are used in this study and the results are compared. Their parameters, as used in energy consumption model, are presented in Table 1. 

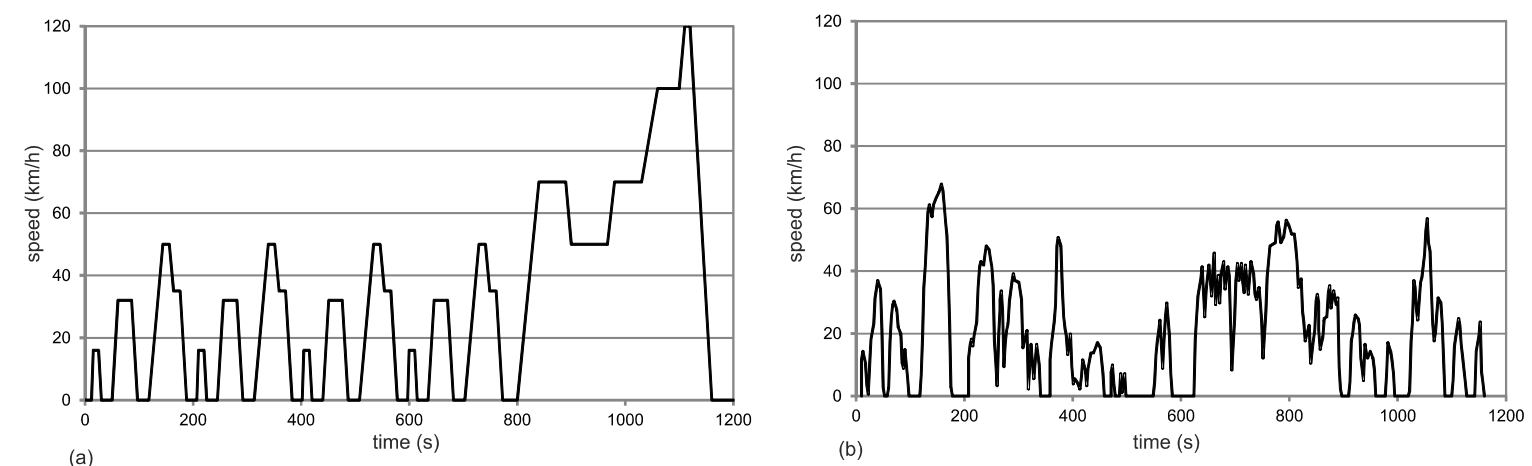

Figure 3. (a) New European and (b) Athens driving cycles

Table 1. Characteristic parameters of the driving cycles

\begin{tabular}{c|cc}
\hline Category & NEDC & $A D C$ \\
\hline Average Velocity & $33.6 \mathrm{~km} \mathrm{~h}^{-1}$ & $19.8 \mathrm{~km} \mathrm{~h}^{-1}$ \\
Root-Mean-Cube Velocity & $53.5 \mathrm{~km} \mathrm{~h}^{-1}$ & $31.2 \mathrm{~km} \mathrm{~h}^{-1}$ \\
Characteristic Acceleration & $0.11 \mathrm{~m} \mathrm{sec}^{-2}$ & $0.25 \mathrm{~m} \mathrm{sec}^{-2}$ \\
Total Trip Time & $1180 \mathrm{sec}$ & $1160 \mathrm{sec}$ \\
\hline
\end{tabular}

\subsection{Passenger cars registered in 2010}

Passenger cars are classified into categories according to the European Classification, based on their length and on their engine characteristics. For the purposes of this study, only five of the categories have been considered (A-mini cars, B-small cars, C-medium cars, D-large cars and SUV) which represent $90 \%$ of the total market share. It is also assumed that all vehicles travel on average a distance of 10,000 km annually in urban areas (I. Ziomas, personal communication, April 13, 2010).

Table 2 exhibits the number of new cars that were registered during the last year (2010), for each one of those five categories and the respective market share as well as the characteristics of a typical vehicle for each category (Ecomodder, 2011; Carfolio, 2011) and its energy consumption (in liters of gasoline per 100 vehicle kilometres), as it was calculated by the model. The mean fuel consumption over all registered cars is 7.6 and $10 \mathrm{~L} / 100 \mathrm{~km}$ for NEDC and ADC, respectively.

Table 2. Vehicles registered in 2010 and their characteristics (AMVIR, 2010)

\begin{tabular}{c|ccccccc}
\hline Category & $\begin{array}{c}\text { Vehicles } \\
\text { Registered } \\
\text { in 2010 }\end{array}$ & $\begin{array}{c}\text { Market } \\
\text { Share }\end{array}$ & $\begin{array}{c}\text { Mass } \\
(\mathrm{kg})\end{array}$ & $\begin{array}{c}\text { Drag } \\
\text { Area } \\
\left(\mathrm{m}^{2}\right)\end{array}$ & $\begin{array}{c}\text { Engine } \\
\text { Efficiency }\end{array}$ & $\begin{array}{c}\text { Fuel Consumption } \\
\left(L_{\text {gas-eq }} / 100 \mathrm{~km}\right)\end{array}$ \\
\hline & 12,436 & $16.5 \%$ & 860 & 0.7 & 0.22 & 6.9 & 8.4 \\
A & 25,129 & $33.4 \%$ & 1040 & 0.57 & 0.25 & 6.2 & 8.2 \\
B & 20,098 & $26.7 \%$ & 1220 & 0.58 & 0.2 & 8.5 & 11.5 \\
C & 5,737 & $7.6 \%$ & 1500 & 0.57 & 0.18 & 10.6 & 14.8 \\
D & 4,330 & $5.7 \%$ & 1340 & 0.94 & 0.22 & 9.4 & 11.6 \\
SUV & \multicolumn{7}{c}{ Mean Fuel Consumption } \\
\hline
\end{tabular}

\subsection{Penetration of parallel hybrid electric and battery electric vehicles}

The first scenario to be examined involves the substitution of all the passenger cars that were registered in 2010 with HEVs and BEVs that already exist in the market. Table 3 presents the characteristics of five indicative new technology passenger cars, which are sold in the Greek market. The same Table presents the fuel consumption as calculated by the energy consumption model. The consumption is expressed in liters of gasoline equivalent $\left(L_{\text {gas-eq }}\right)$ per 100 vehicle kilometers. The gasoline equivalent has been proposed by the U.S. EPA to compare energy consumption of alternative fuel vehicles, with the fuel economy of conventional internal combustion vehicles (U.S. EPA, 2010). 
The mean fuel consumption of all passenger cars has been reduced by $42 \%$ on NEDC and $45 \%$ on ADC (Figure 4). Subsequently, the fuel consumption in the transport sector of Athens Area has been reduced by $21,740 \mathrm{~m}^{3}$ using the NEDC or by $30,540 \mathrm{~m}^{3}$ using the ADC. Taking the gasoline emission factor equal to $2.325 \mathrm{tCO}_{2} \mathrm{~m}^{-3}$, the total reduction of the emissions is $50,545 \mathrm{tCO}_{2}$ (NEDC) $-71,000 \mathrm{tCO}_{2}$ (ADC) (Figure 5). Comparing to the total $\mathrm{CO}_{2}$ emissions from private cars circulating in the area in 2010, which is estimated to 4,706,000 $\mathrm{tCO}_{2}$ (I. Ziomas, personal communication, April 13, 2010), the total reduction of emissions is about $1.1 \%$. Assuming a five year horizon for the application of this measure and that the number of newly registered cars remains the same for the next five years, the total emissions' reduction may reach from $5.5 \%$ (NEDC) to $7.5 \%$ (ADC).

Table 3. Characteristics of the existing new technology vehicles

\begin{tabular}{c|lccccccc}
\hline Category & Model & $\begin{array}{c}\text { Techno- } \\
\text { logy }\end{array}$ & $\begin{array}{c}\text { Mass } \\
(\mathrm{kg})\end{array}$ & $\begin{array}{c}\text { Drag } \\
\text { Area } \\
\left(\mathrm{m}^{2}\right)\end{array}$ & $\begin{array}{c}\text { Engine } \\
\text { Efficiency }\end{array}$ & $\begin{array}{c}\text { Fuel } \\
\text { Consumption } \\
\left(L_{\text {gas-ed }} / 100 \mathrm{~km}\right)\end{array}$ \\
\hline & Citroën C1 ev'ie & BEV & 905 & 0.62 & 0.8 & 1.9 & 2.2 \\
\cline { 5 - 8 } A & Honda Jazz & HEV & 1162 & 0.72 & 0.35 & 4.8 & 5.8 \\
B & Honda Insight & HEV & 1204 & 0.57 & 0.34 & 4.7 & 6.0 \\
C & Toyota Prius & HEV & 1370 & 0.54 & 0.37 & 4.8 & 6.6 \\
D & Lexus RX Hybrid & HEV & 2110 & 0.9 & 0.37 & 7.0 & 9.2 \\
\hline \multicolumn{7}{c}{ Mean Fuel Consumption } \\
\hline \multicolumn{7}{c}{}
\end{tabular}

\subsection{Penetration of fuel cell electric vehicles}

In the second scenario, the penetration of FCEVs in the Greek market is examined. For the purpose of this analysis, five FCEVs are designed on the basis of the conventional vehicles' performance indicators as shown in Table 4. The characteristics of the vehicles designed as well as the fuel consumption calculated by the energy consumption model are presented in Table 5.

Table 4. Vehicle performance indicators

\begin{tabular}{c|cccc}
\hline Category & $\begin{array}{c}\text { Top Speed } \\
\left(\mathrm{km} \mathrm{h}^{-1}\right)\end{array}$ & $\begin{array}{c}\text { Acceleration } \\
0-100(\mathrm{sec})\end{array}$ & $\begin{array}{c}\text { Gradability } \\
\left(\mathrm{km} \mathrm{h}^{-1}\right)\end{array}$ & $\begin{array}{c}\text { Fuel Range } \\
(\mathrm{km})\end{array}$ \\
\hline A & 155 & 14.0 & $100 / 6.5 \%$ & 500 \\
B & 175 & 13.4 & $100 / 6.5 \%$ & 677 \\
C & 178 & 14.2 & $100 / 6.5 \%$ & 658 \\
D & 192 & 12.9 & $100 / 6.5 \%$ & 625 \\
SUV & 175 & 11.8 & $100 / 6.5 \%$ & 630 \\
\hline
\end{tabular}

Table 5. Characteristics of the designed fuel cell electric vehicles

\begin{tabular}{c|cccc}
\hline Category & $\begin{array}{c}\text { Mass } \\
(\mathrm{kg})\end{array}$ & $\begin{array}{c}\text { Fuel Cell Power } \\
(\mathrm{hp})\end{array}$ & \multicolumn{2}{c}{$\begin{array}{c}\text { Fuel Consumption } \\
\left(L_{\text {gas-eq }} / 100 \mathrm{~km}\right)\end{array}$} \\
\hline & & & NEDC & ADC \\
A & 923 & 68 & 3.1 & 3.8 \\
B & 1146 & 84 & 3.3 & 4.4 \\
C & 1261 & 88 & 3.5 & 4.7 \\
D & 1566 & 118 & 3.9 & 5.6 \\
SUV & 1686 & 138 & 4.7 & 6.1 \\
\hline \multicolumn{2}{c}{ Mean Fuel Consumption } & 3.5 & 4.6 \\
\hline
\end{tabular}

The decrease in the mean fuel consumption resulting from the substitution of the vehicles registered in 2010 with FCEVs is almost $54 \%$ for both driving cycles (Figure 4). The subsequent total reduction of gasoline consumption is $27,941 \mathrm{~m}^{3}$ and the corresponding emissions' reduction is $64,963 \mathrm{tCO}_{2}$ when using the NEDC (Figure 5). The same figures increase significantly when using ADC and are 
equal to $36,600 \mathrm{~m}^{3}$ and $85,100 \mathrm{tCO}_{2}$ respectively. Considering again a five year horizon, the total reduction almost reaches $7 \%$ (NEDC) - $9 \%$ (ADC).

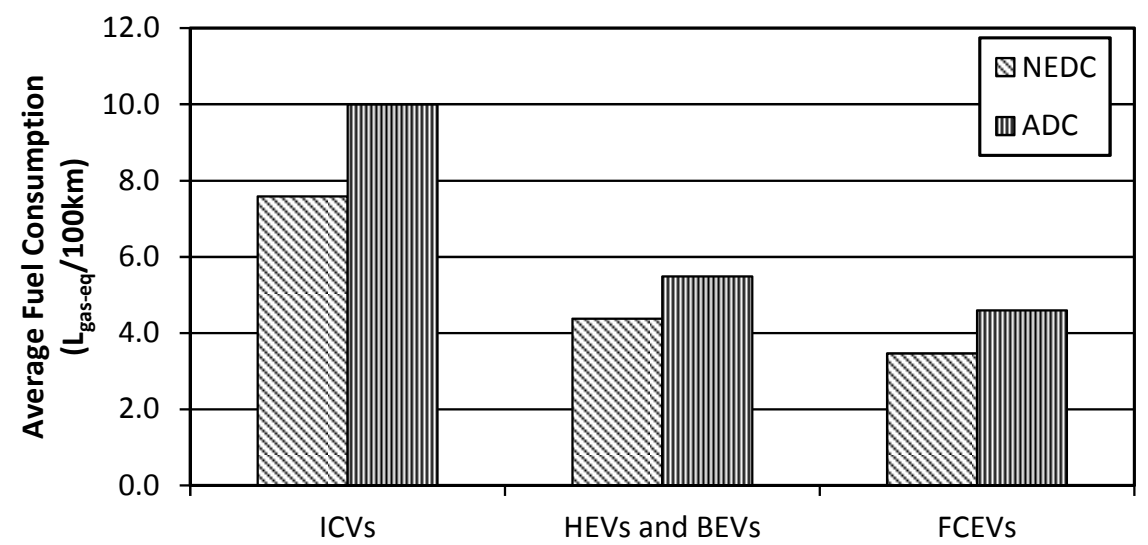

Figure 4. Average fuel consumption ( $\mathrm{L}_{\text {gas-eq }} / 100 \mathrm{~km}$ ) for each scenario and driving cycle

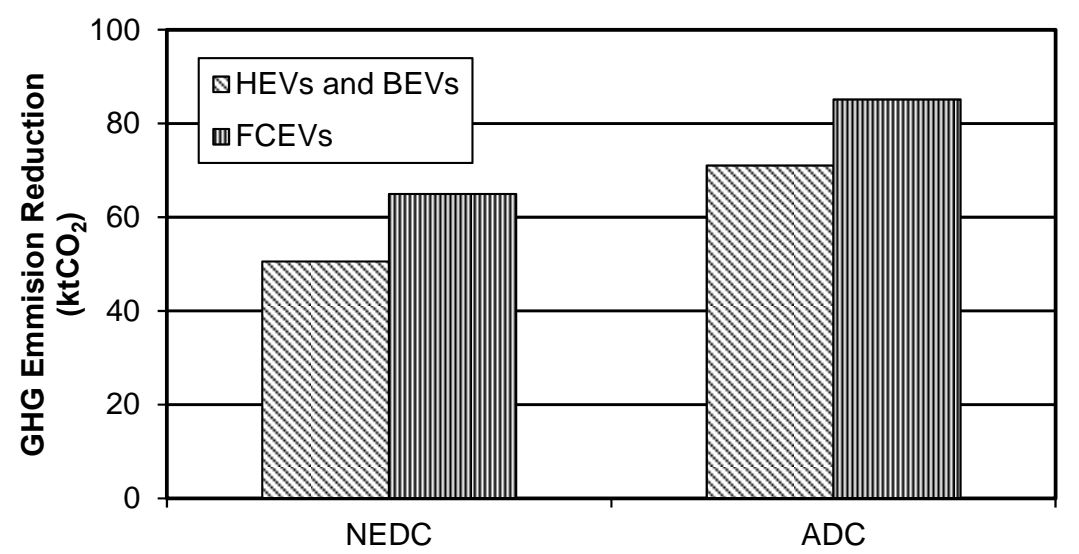

Figure 5. GHF emission reduction for each scenario and driving cycle

\section{CONCLUSIONS}

It is obvious that the substitution of the existing private cars that were bought in 2010 by new technology vehicles could improve the reduction of energy consumption and greenhouse gas emissions in the transport sector. Results indicate a $5.5 \%$ to $9 \%$ reduction of the $\mathrm{CO}_{2}$ emissions in the Greater Athens Area by applying this measure for five years.

FCEVs are more environmentally friendly and the transition of the transportation sector to their use will represent one of the bigger steps towards the hydrogen economy. However, this substitution should not be examined as a stand-alone measure. It should be a part of wider action plan which will include incentives for withdrawing old vehicles and subsidies for buying new technology passenger cars. This will result in the quicker penetration of new technologies in the fleet and the removal of the older and more polluting vehicles.

The study does not cover a relative cost comparison. However, a cost analysis of the proposed scenarios cannot be easily performed, since FCVEs are not yet mature as a commercial technology. This analysis, as well as the examination of other alternatives (such as biofuel cars), is considered as a future extension.

\section{REFERENCES}

AMVIR (2010) Association of Motor Vehicle Importers-Representatives Database URL: http://www.seaa.gr/en/statistics/registration (accessed 01/04/2011)

Arampatzis G., Kiranoudis C.T., Scaloubacas P. and Assimakopoulos D. (2004) A GIS-based decision support system for planning urban transportation policies, Journal of Operational Research, 152, 465475.

Carfolio (2011) Technical Specifications of Vehicles URL: http://www.carfolio.com (accessed 01/04/2011) 
Ecomodder (2011) Vehicle Coefficient of Drag List URL: http://ecomodder.com/wiki/index.php/Vehicle_Coefficient_of_Drag_List (accessed 01/04/2011)

Ministry of Environment, Energy and Climate Change (2009) Annual Inventory Submission under the Convention and the Kyoto Protocol for Greenhouse and other Gases for the Years 1990-2007.

Pitsas K. (2003) Vehicle technical inspection. Driving cycles and atmospheric pollution. PhD thesis. National Technical University of Athens, School of Chemical Engineering. Athens, Greece.

Simpson A. (2005) Parametric modeling of energy consumption in road vehicles, D.Phil Thesis, Sustainable Energy Research Group, School of Information Technology and Electrical Engineering, University of Queensland, Australia, 27-80.

Tzirakis E., Pitsas K., Zannikos F. and Stournas S. (2006) Vehicle emissions and driving cycles: Comparison of the Athens Driving Cycle (ADC) with ECE-15 and European Driving Cycle (EDC), Global NEST Journal, 8(3), 282-290.

U.S. EPA, (2010), EPA and NHTSA Propose Changes to the Motor Vehicle Fuel Economy Label.

Veziroglu A. and Macario R. (2011) Fuel cell vehicles: State of the art with economic and environmental concerns, International Journal of Hydrogen Energy, 36, 25-43.

Xiaolan W., Binggang C., Xueyan L., Jun X. and Xiaolong R. (2011) Component sizing optimization of plug-in electric vehicles, Applied Energy, 88, 799-804. 